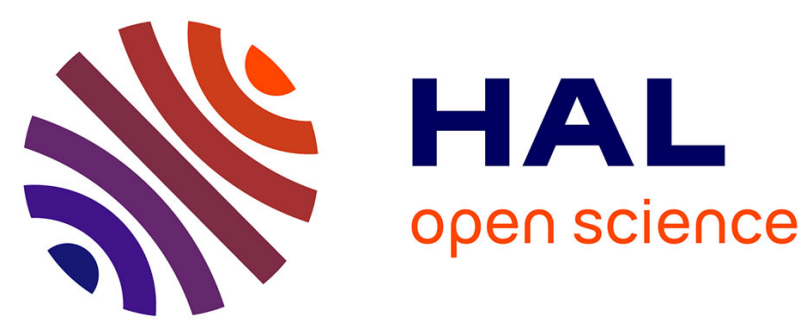

\title{
Double functionalization for the design of innovative craniofacial prostheses
}

\author{
Caroline Pereira, Jean-Sebastien Baumann, Patrick Masson, Genevieve \\ Pourroy, Adele Carradò, Veronique Migonney, Celine Falentin-Daudre
}

\section{To cite this version:}

Caroline Pereira, Jean-Sebastien Baumann, Patrick Masson, Genevieve Pourroy, Adele Carradò, et al. Double functionalization for the design of innovative craniofacial prostheses. JOM Journal of the Minerals, Metals and Materials Society, 2021, 10.1007/s11837-021-04997-0 . hal-03510664

\section{HAL Id: hal-03510664 \\ https://hal.science/hal-03510664}

Submitted on 4 Jan 2022

HAL is a multi-disciplinary open access archive for the deposit and dissemination of scientific research documents, whether they are published or not. The documents may come from teaching and research institutions in France or abroad, or from public or private research centers.
L'archive ouverte pluridisciplinaire HAL, est destinée au dépôt et à la diffusion de documents scientifiques de niveau recherche, publiés ou non, émanant des établissements d'enseignement et de recherche français ou étrangers, des laboratoires publics ou privés. 


\title{
Double functionalization for the design of innovative craniofacial prostheses
}

\section{CAROLINE PEREIRA $^{1}$, JEAN-SEBASTIEN BAUMANN ${ }^{1}$, PATRICK MASSON ${ }^{2}$, GENEVIEVE POURROY $^{2}$, ADELE CARRADOे ${ }^{2}$, VERONIQUE MIGONNEY ${ }^{1}$, CELINE FALENTIN-DAUDRE ${ }^{1 *}$}

${ }^{1}$ Université Sorbonne Paris Nord, Institut Galilée, LBPS/CSPBAT, CNRS UMR 7244, Villetaneuse, France.

${ }^{2}$ Université de Strasbourg, Institut de Physique et Chimie des Matériaux de Strasbourg (IPCMS), CNRS UMR 7504, Strasbourg, France.

*Corresponding author: falentin-daudre@univ-paris13.fr

\begin{abstract}
Titanium (Ti) is the most commonly used material for cranial prostheses. However, this material does not exhibit the same mechanical properties as the bone. Incorporating polymers onto Ti by combining both their properties is a solution to overcome this issue. Thus, sandwich materials made of two Ti skin sheets and a poly(methyl methacrylate) (PMMA) core are promising structures to design biomedical prostheses. The "grafting to" and "grafting from" procedures to functionalize the Ti/PMMA interface are described in this paper as two strategies for chemically connecting PMMA chains on Ti surfaces. The advantage of the first approach is the capacity to control the architecture of the grafted PMMA on Ti. Moreover, a method for selectively grafting a bioactive polymer such as poly(sodium styrene sulfonate) (PNaSS) on one side of the Ti and PMMA on the other side is developed. This contribution presents efficient ways of functionalizing Ti for biomedical applications.
\end{abstract}

\section{Introduction}

Cranioplasty is a surgical procedure used for the reconstruction of craniofacial bone substances losses. These bone losses are mainly due to skull injuries such as head traumas, infections, or pathologies requiring the removal of tumors. Therefore, it is necessary to develop cranial devices to replace a part of the removed bone flap. However, tailoring the optimal interaction of craniofacial implants with bone tissues is a challenge. Consequently, there is a great interest in creating composite designs with mechanical and biological properties nearer to the surrounding tissues.

The materials widely manufactured for cranial prostheses are polymers such as poly (methyl methacrylate) (PMMA), ceramics (hydroxyapatite), and metals such as titanium (Ti) [1,2]. Ti remains the most used material for cranioplasty due to its acceptable biocompatible properties. The spontaneous formation of a superficial oxide layer that grows with its exposure to air explains its numerous characteristics. This amorphous layer of 3 to $7 \mathrm{~nm}$ thickness, mainly composed of $\mathrm{Ti}_{\text {oxide }} \mathrm{TiO}_{2}$, chemically stabilizes the material's structure. [35]. Currently, custom-made Ti implants are manufactured on the market. These prostheses are fabricated using a laser beam additive technology called selective laser melting (SLM). It is a relevant example of building light Ti skull and mandible prostheses [6-9]. Moreover, PMMA is also mainly used in cranioplasty due to its interesting biocompatibility, low cost, and strength [10,11]. The first PMMA cranioplasty was performed by Zander in 1940 [12].

However, these materials have many disadvantages, such as their lack of mechanical properties with bone or densities [13]. In addition, unmodified Ti-based materials tend to initiate the development of a fibrous layer following several years of implantation, prompting continuous loss of osseointegration [14,15]. Since these materials alone cannot optimally solve these discrepancies, the strategy proposed is to combine two different materials: polymers and metals, to design innovative hybrid structures called sandwich structures. Indeed, those structures exploit the high bending resistance of the metals [16] and the lightweight of polymers [17]. For nonbiological applications, the bonding between polymer and metal is accomplished utilizing an epoxy resin which is cytotoxic and therefore cannot be considered for biological applications [18]. On the other hand, the bonding between metals and polymers is usually a mechanical interface since both materials do not chemically bond spontaneously. In this circumstance, procedures guaranteeing a robust covalent bond between a thick polymer layer and the Ti are needed [19]. Indeed, these techniques would allow structures that can handle mechanical properties, such as Young's modulus, for better implant/bone interface.

Furthermore, the prosthesis must be biocompatible to be well integrated by living bone tissues. In this regard, various strategies have been created to advance osseointegration between the implant and the surrounding bone $[20,21]$. Previous works carried out by our laboratory exhibited that the long-term response of implants can be improved by the grafting of bioactive polymers such as poly(sodium styrene sulfonate) (PNaSS), PMMA, and poly(methacryloyl phosphate) [22,23]. In vitro and in vivo studies were conducted to follow the interactions 
between the bioactive materials and living tissues. It has been shown that the functional groups of PNaSS are biologically active on osteoblasts cells since the cell adhesion proteins adopt a conformation more conducive to the adhesion and then to the osteoblast cells' development. [24,25]. The grafting of PNaSS presents a biocompatibility interest, as it makes the implant surface hydrophilic, charged, and bacteriostatic. Recently, the grafting of PNaSS was successfully established using radicals under ultraviolet (UV) irradiation [26,27].

In general, two unique methodologies have been used to interface polymer chains on metal surfaces: the covalent connection of end-functionalized polymers joining an anchor molecule ("grafting to") and the in situ polymerization started from the surface ("grafting from") [28]. It is in this perspective that in their previous investigations [29], Reggente et al. have designed innovative epoxy resin-free sandwich materials composed of $\mathrm{Ti}$ and polymer sheets (Ti/PMMA/Ti) by developing the "grafting from" method [30]. This technique involves the grafting of PMMA using atom transfer radical polymerization (ATRP) [31-33]. ATRP is a form of living radical polymerization used to carry out controlled radical polymerization (CRP). Another example of the CRP method is the reversible addition-fragmentation transfer (RAFT) polymerization that can control the polymer structure. Both techniques allow grafting covalently chosen polymers and controlling their architecture, thicknesses, and compositions.

Several covalent grafting techniques can thus be used to graft PMMA chains onto Ti. Referring to the previous work developed by our team [34,35], here two different ways of linking PMMA chains onto Ti surfaces are reported: (i) the "grafting to" technique using an anchor molecule to which PMMA chains of various lengths synthesized by RAFT polymerization are covalently attached and (ii) the "grafting from" technique including the direct polymerization of PMMA by surface oxidation and UV irradiations. Moreover, to confer biological properties to the Ti/PMMA hybrid surfaces, a UV grafting technique that permits to selectively graft the PMMA onto one side of the Ti surface and PNaSS onto the opposite side of the surface has been developed.

In this article, the polymers synthesized by RAFT polymerization were characterized by conventional methods (nuclear magnetic resonance (NMR), size exclusion chromatography (SEC), and attenuated total reflection-Fourier-transformed infrared (FTIR)). In addition, the functionalized surfaces were characterized by FTIR, water contact angle measurements (WCA), Oxford energy dispersive spectroscopy (EDS), and the toluidine blue colorimetric method (TB).

\section{Materials and Methods}

a. Materials

All chemical products were acquired from commercial providers and were utilized as received.

One and half-centimeter diameter commercially pure, grade $2 \mathrm{Ti}$ was purchased from Goodfellow. The two faces of the Ti were polished consecutively with 500 and 1200 grit SiC papers. After the polishing process, the $\mathrm{Ti}$ disks were successively cleaned twice in an acetone bath, once in cyclohexane bath, once in isopropanol bath, and once in distilled water $\left(\mathrm{dH}_{2} \mathrm{O}\right)$ bath with sonication for $15 \mathrm{~min}$. Ti disks were then dried in an oven at $50^{\circ} \mathrm{C}$. Afterward, Ti surfaces were chemically etched with Kroll's reagent (2\% hydrofluoric acid, Sigma; $10 \%$ $\mathrm{HNO}_{3}$, Acros, and $88 \% \mathrm{dH}_{2} \mathrm{O}$ ) for 1 min with stirring followed by $15 \mathrm{~min}$ of sonication cleaning in five consecutive water baths.

The dopamine acrylamide (DA) anchor group synthesis was performed based on the protocol established by Chouirfa et al. [34].

Methyl methacrylate (MMA) was purified over a basic alumina column to remove the stabilizer. The description of the synthesis procedures used to prepare the PMMA via RAFT polymerization and thiolation of PMMA are provided in the supplementary material. The additional material also describes experimental details for the nuclear magnetic resonance (NMR) and size exclusion chromatography (SEC) methods used to characterize the synthesized PMMA samples.

Sodium styrene sulfonate (NaSS, Sigma) was purified by recrystallization in a mixture of ethanol/water (Carlo Erba) $(10: 90 \mathrm{v} / \mathrm{v})$ overnight at $70^{\circ} \mathrm{C}$. The purified $\mathrm{NaSS}$ was dried under atmospheric pressure at $50^{\circ} \mathrm{C}$ overnight and then stored at $4^{\circ} \mathrm{C}[27,37]$.

The UV source used for the grafting procedure comes from a Lot Quantum Design UV lamp with a generated power from $200 \mathrm{~W}$ to $500 \mathrm{~W}$, at $365 \mathrm{~nm}$ under average temperature and pressure conditions.

\section{b. Methods: The grafting processes}

i. Indirect grafting of MMA process

Activation: After Kroll's treatment, Ti samples were activated according to the protocol established by Reggente et al. $[29,36]$. The Ti disks were immersed for $1 \mathrm{~h}$ into a $2 \mathrm{M}$ sodium hydroxide $(\mathrm{NaOH})$ solution heated at $80^{\circ} \mathrm{C}$ in a Teflon beaker. Ti disks were suspended in the reactive media with a Ti wire during the activation step 
to avoid contact. Afterward, the alkali-activated Ti samples were suspended in a flask containing $\mathrm{dH}_{2} \mathrm{O}$ water for $1 \mathrm{~h}$ at $60^{\circ} \mathrm{C}$. This cleaning procedure was established to remove any traces of concentrated $2 \mathrm{M} \mathrm{NaOH}$ solution.

Indirect grafting of MMA onto Ti: The surface functionalization with the catechol derivative was described in detail by Chouirfa et al. [34]. This process consists of a three-step methodology (Figure 1). Well-defined molecular weight (10, 16, and $50 \mathrm{kDa}$ ) RAFT synthetized PMMA bearing thiol end group (PMMA-SH) were covalently grafted via thiol-ene click reaction onto Ti substrates modified with the DA. More details about the dopamine adhesion and the coupling reaction of the polymer are provided in the supplementary material.

\section{ii. Direct grafting of MMA process}

Methyl methacrylate (MMA) with a concentration of $1.5 \mathrm{M}$ - purified from its stabilizer by column chromatography on basic aluminum oxide - was added to a $100 \mathrm{~mL}$ round bottom flask containing dimethyl sulfoxide (DMSO) solvent. First, the solution was degassed with argon for $30 \mathrm{~min}$, and then the activated Ti surfaces (with the procedure described above (i)) were rapidly introduced within the solution. Next, the round bottom flask containing the MMA/DMSO solution and the Ti surfaces was irradiated with UV light $(365 \mathrm{~nm}, 160$ $\mathrm{mW} / \mathrm{cm}^{2}$ ) at ambient temperature with stirring for $1 \mathrm{~h}$. (Figure 1). The grafted surfaces were then rinsed for $48 \mathrm{~h}$ with $\mathrm{dH}_{2} \mathrm{O}$ and dried overnight at $37^{\circ} \mathrm{C}$ before any characterization.

\section{iii. Double face functionalization}

The selectivity of this functionalization method was made possible due to UV irradiation and the set-up implemented. Indeed, only the Ti surface directly exposed to the UV beam of the mercury lamp was able to graft the chosen polymer through the grafting process. Therefore, as a part of our study, this protocol was established strictly following the PMMA grafting protocol using the "grafting from" procedure, followed by the "grafting from" process of PNaSS.

Ti-PMMA-Ti-PNaSS procedure: Ti samples were activated according to the protocol established by Reggente $e t$ al. [29, 36]. The Ti disks were immersed for $1 \mathrm{~h}$ into a $1 \mathrm{M}$ sodium hydroxide $(\mathrm{NaOH})$ solution, heated at $80^{\circ} \mathrm{C}$ in a Teflon beaker. Ti disks were suspended in the reactive media with a Ti wire during the activation step to avoid contact. Afterward, the alkali-activated Ti samples were suspended in a flask containing $\mathrm{dH}_{2} \mathrm{O}$ for $1 \mathrm{~h}$ at $60^{\circ} \mathrm{C}$. Then, Ti samples were immersed in a degassed DMSO solution of MMA (1.5M). The round bottom flask, containing the MMA/DMSO solution and Ti surfaces, was irradiated with UV light $\left(365 \mathrm{~nm}, 160 \mathrm{~mW} / \mathrm{cm}^{2}\right)$ at ambient temperature with stirring for $1 \mathrm{~h}$. For this first grafting, the face A has been exposed under UV irradiations. The grafted surfaces were then rinsed for $48 \mathrm{~h}$ with $\mathrm{dH}_{2} \mathrm{O}$. After the washing step, Ti samples were immersed in a degassed and aqueous solution of NaSS monomer $(0.7 \mathrm{M})$. The round bottom flask containing the samples, the solution, and the face B of Ti samples were placed under UV irradiations $\left(365 \mathrm{~nm}, 160 \mathrm{~mW} / \mathrm{cm}^{2}\right)$ at room temperature with stirring for $1 \mathrm{~h}$. Finally, grafted surfaces were then rinsed for $48 \mathrm{~h}$ with $\mathrm{dH}_{2} \mathrm{O}$.

\section{Surfaces characterizations}

Each surface functionalization was followed by attenuated total reflection Fourier-transform infrared spectroscopy (ATR-FTIR) by water contact angle measurement (WCA). The grafting degree of PNaSS was evaluated by the toluidine blue colorimetric method.

Fourier-transform infrared spectroscopy (FTIR) The Fourier-transformed infrared (FTIR) spectra were acquired between 4000 and $600 \mathrm{~cm}^{-1}$ in attenuated total reflectance mode. Ti samples were pressed against a diamond crystal $\left(4000-500 \mathrm{~cm}^{-1)}\right.$ for acquirements (512 scans). Each spectrum was then fitted and analyzed.

EDS element chemical analysis This analysis was performed through scanning electron microscopy (SEM, Hitachi TM300) combined with Oxford energy dispersive spectroscopy (EDS). The instrument operated at $5 \mathrm{kV}$ to $15 \mathrm{kV}$.

Water Contact angle measurements (WCA) The wettability after each surface treatment step was analyzed by WCA measurements using the DAS10 goniometer from Kruss. For each measure, $2 \mathrm{ul}$ of $\mathrm{dH}_{2} \mathrm{O}$ were dropped onto the surface. The dropped image was taken 20 seconds after the water drop contact with the surface. The software from the photo taken then measured the WCA. Three measurements were taken and averaged.

Toluidine blue (TB) colorimetry assay To characterize the quantification of PNaSS grafted onto Ti surfaces, toluidine blue (TB) colorimetric technique was carried out according to the protocol established by Helary et al. [37]. TB is a chromophore molecule that absorbs in the visible at $633 \mathrm{~nm}$. This molecule has the particularity to complex via its $\mathrm{N}^{+}\left(\mathrm{CH}_{3}\right)_{2}$ groups with anionic groups (sulfonate $\mathrm{SO}_{3}{ }^{-}$group of the NaSS). First, PNaSS grafted and washed samples were immersed in the dye solution $(0.5 \mathrm{mM}$ at pH $=10)$ for complexation for $6 \mathrm{~h}$ at $30^{\circ} \mathrm{C}$. The excess of TB was removed with 3 washings with a solution of $\mathrm{NaOH}\left(10^{-3} \mathrm{M}\right.$, three times $\left.5 \mathrm{~min}\right)$. Then, complexed TB sample surfaces were de-complexed by putting the samples in acetic acid/water solution $(50 / 50 \mathrm{v} / \mathrm{v})$ for $24 \mathrm{~h}$. The concentration of TB was then quantified by UV-visible spectroscopy (PerkinElmer lambda 25 spectrometer). 
TB assays were carried out onto six samples for each condition. According to Ikada et al. [38], one mole of TB molecule complexes with one mole of sulfonate $\left(-\mathrm{SO}_{3}{ }^{-}\right)$. Non-grafted Ti samples were used as controls and were found not to react with the TB solution. Therefore, three Ti samples were used per analysis.

\section{Results and discussion}

\section{a. Activation of Ti surfaces}

The activation procedure aimed to prompt active spots on the Ti surface to graft the polymer. In the past, our laboratory was using acidic oxidation to create a surface layer of Ti hydroxide (Ti-OH) and titanium peroxides (Ti-OOH). However, since these hydroperoxides groups are not stable enough, it has been decided to activate the Ti surface with basic oxidation.

Based on the literature, an alkali activation was performed to activate the surface. The characterizations work done by M. Reggente et al. have demonstrated that the layer generated by the sodium hydroxide solution onto Ti surfaces has pore size ranges between 50 to $200 \mathrm{~nm}$ and is uniformly spread on the whole Ti surface (20 $\mathrm{mm}$ in diameter and $3 \mathrm{~mm}$ thick of commercially pure grade $4 \mathrm{Ti}$ ) [29]. In our type of Ti surface (15 mm in diameter and $1.5 \mathrm{~mm}$ thick of commercially pure grade $2 \mathrm{Ti}$ ), it has been noticed that the surfaces do not exhibit the same color depending on the oxidation (acid or alkaline). A light yellow Ti surface color was observed with Piranha solution and dark blue color with the alkaline oxidation (details descriptions are provided in the supplementary material). The color varies with the thickness of the Ti oxide layer. According to the literature [38], as long as the oxide layer is thin (20 to $30 \mathrm{~nm}$ ), it is transparent, and the Ti sample keeps its metallic luster. As soon as the oxide thickens and reaches $40 \mathrm{~nm}$, the surface acquires a color due to light interference effects. By referring to the table of the colours of titanium oxide films as a function of the thickness of the oxide layer, established by N.P. Peksheva et al, it can be assumed that the oxide layer's thickness would be, respectively, around $35 \mathrm{~nm}$ for acid oxidation and about $50 \mathrm{~nm}$ for alkaline oxidation.

The EDS element chemical analysis revealed several atoms (C, O, Na, Ti), mainly $\mathrm{Na}$ and $\mathrm{O}$, essential layer compounds formed by the basic activation (Table 1). Moreover, the hydrophilicity character of the surface after the activation was shown by the water contact angle measurement. For example, the contact angle of the control Ti surface (polished Ti disk, cleaned with Kroll's reagent and oxidized with Piranha solution) was around $66^{\circ}$. After the activation step, the surface gave a contact angle around $42^{\circ}$ showing the presence of hydroxyl groups onto Ti (Figure 2).

\section{b. Ti functionalization with "grafting to" and "grafting from" procedure}

The grafted PMMA Ti surface prepared via the "grafting to" technique requires the addition of an anchoring molecule (dopamine acrylamide) to link the PMMA chains to the Ti surface (Figure 1).

This procedure was done in four steps (Figure 1): 1. Ti surface was activated with NaOH. 2. The surface was functionalized with dopamine acrylamide. 3. PMMA was synthesized by RAFT polymerization to generate a thiol function. 4 . The thiol-end polymer chains were attached to the Ti surface by a thiolene click reaction.

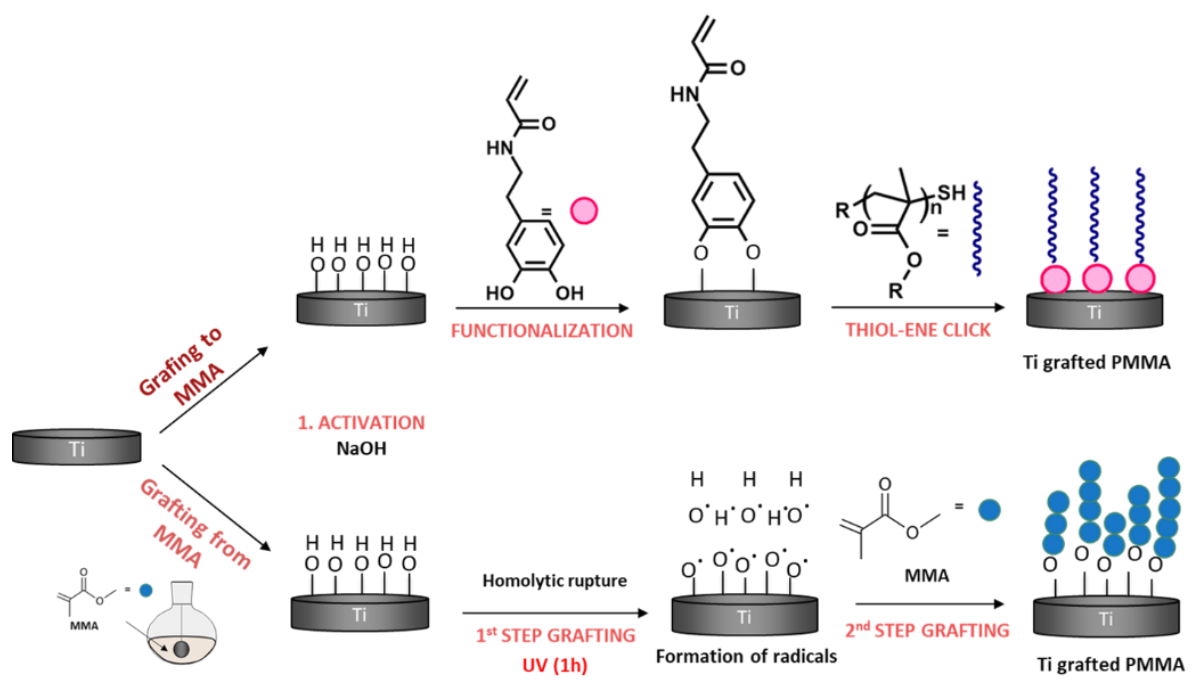

Figure 1: The PMMA-grafted Ti surfaces were designed using the following methodology: "Grafting from" includes UV PMMA grafting and gives non-control sized polymer chains, whereas the "grafting to" allows the grafting of polymer chains of controlled and specific size. 
FTIR spectra of the PMMA grafted Ti with this method (blue curve) and synthesized PMMA powders (yellow curve) are represented in Figure 2. Both ranges contain the signal of the carbonyl group peak $(\mathrm{C}=\mathrm{O}$ at $\left.1725 \mathrm{~cm}^{-1}\right)$ and the $\alpha$-methyl group vibrations $\left(\alpha-\mathrm{CH}_{3}\right.$ at $2993 \mathrm{~cm}^{-1}$ and $\left.2945 \mathrm{~cm}^{-1}\right)$, confirming that PMMA was successfully grafted onto the Ti surface. Other absorption bands were observed at $1438 \mathrm{~cm}^{-1}\left(-\mathrm{CH}_{2}\right.$ bending vibration), $1060 \mathrm{~cm}^{-1}$ (C-O bond stretching), and 1380-749 $\mathrm{cm}^{-1}$ ( $\alpha$-methyl group vibrations). The absorption bands around $800 \mathrm{~cm}^{-1}$ on the Ti grafted are attributable to Ti-O bonds. This observation through FTIR analyses indicates that the grafting of the controlled-sized PMMA chains is not homogeneous. Indeed, it has been observed that in the "grafting to" method, the grafted polymer on the Ti surface, polymerized by RAFT synthesis, results in a controlled architecture, but the surface coverage remains inhomogeneous.

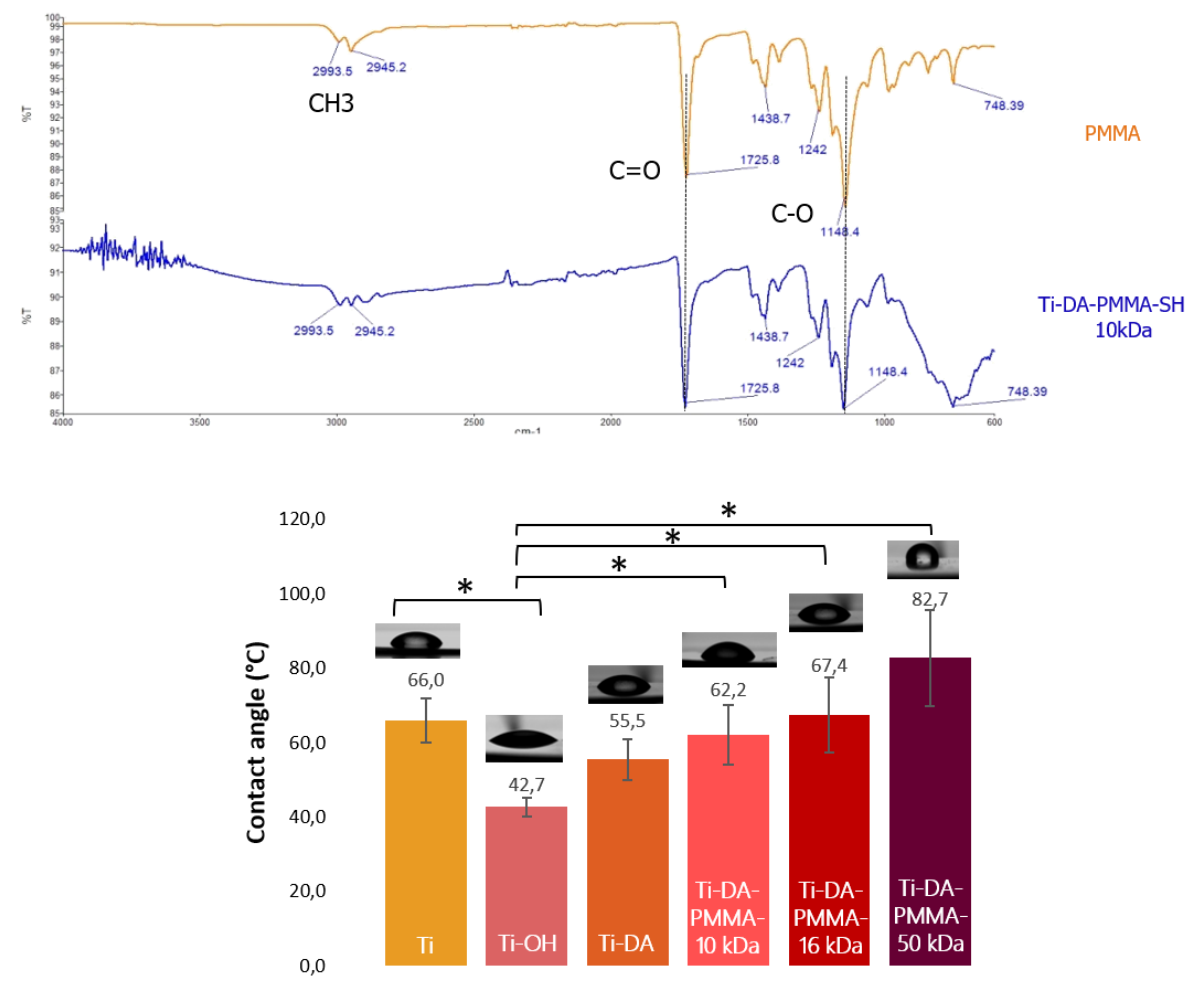

Figure 2: FTIR spectrum and WCA measurements result for the functionalized Ti with "grafting to" procedure.

In addition, the hydrophilicity/hydrophobicity of the surface was measured by the water contact angle (WCA) method (Figure 2). When the surface is functionalized with the anchor molecule, the contact angle of the activated surface increases by about $13^{\circ}$. The surface becomes less hydrophilic with the presence of dopamine acrylamide. Ti surfaces grafted with $10 \mathrm{kDa}, 16 \mathrm{kDa}$, and $50 \mathrm{kDa}$ PMMA-SH gave contact angles of $62^{\circ} \pm 8,67^{\circ} \pm 10$ and $83^{\circ} \pm 13$, respectively. These contact angles increase with the grafting of PMMA which is a hydrophobic polymer. It is interesting to notice that as the size of the PMMA chains increases, the surface becomes more hydrophobic. On the other hand, the standard deviation also increases, showing that the surface coverage loses homogeneity with high-length PMMA chains. This technique, coupled with infrared spectra, demonstrates the same conclusions.

The second method proposed in this study is a direct grafting technique. First, the MMA monomer is directly placed in a solution in a solvent, which solubilizes it (DMSO). Then, the Ti surfaces activated by $\mathrm{NaOH}$ are introduced so that the grafting with UV occurs. The UV irradiation allows radicals on the Ti surface, which will then initiate the MMA polymerization. The direct grafting of MMA is very efficient since it will avoid the synthesis of the anchor molecule by allowing a direct grafting of the solubilized monomer in contact with the surface under UV.

FTIR spectra of the PMMA grafted Ti with this "grafting from" method (pink curve), and MMA monomer liquid (black curve) are represented in Figure 3. The principal proof of PMMA formation came from the vanishing of the signal due to the $\mathrm{C}=\mathrm{C}$ stretching vibration mode of the vinyl group of the monomer $\left(1601 \mathrm{~cm}^{-1}\right)$. The FTIR spectrum of the PMMA grafted Ti attests to the success of direct grafting. Other characteristic peaks of PMMA, 
described earlier, are present. The peaks are more defined, and the spectrum is more refined than the one obtained by the "grafting to" method.

In addition, the contact angle of a PMMA grafted surface is around $102.0^{\circ} \pm 0.8$ (Figure 3). Furthermore, the standard deviation is acceptable, showing that the surface coverage homogeneity of PMMA is likely uniform on the Ti surface.

The results obtained by the FTIR spectrum combined with the contact angle result show that this direct grafting method is more efficient than the indirect grafting method. Therefore, direct grafting allows obtaining a better covering of the surface by the PMMA while having a straightforward grafting protocol.
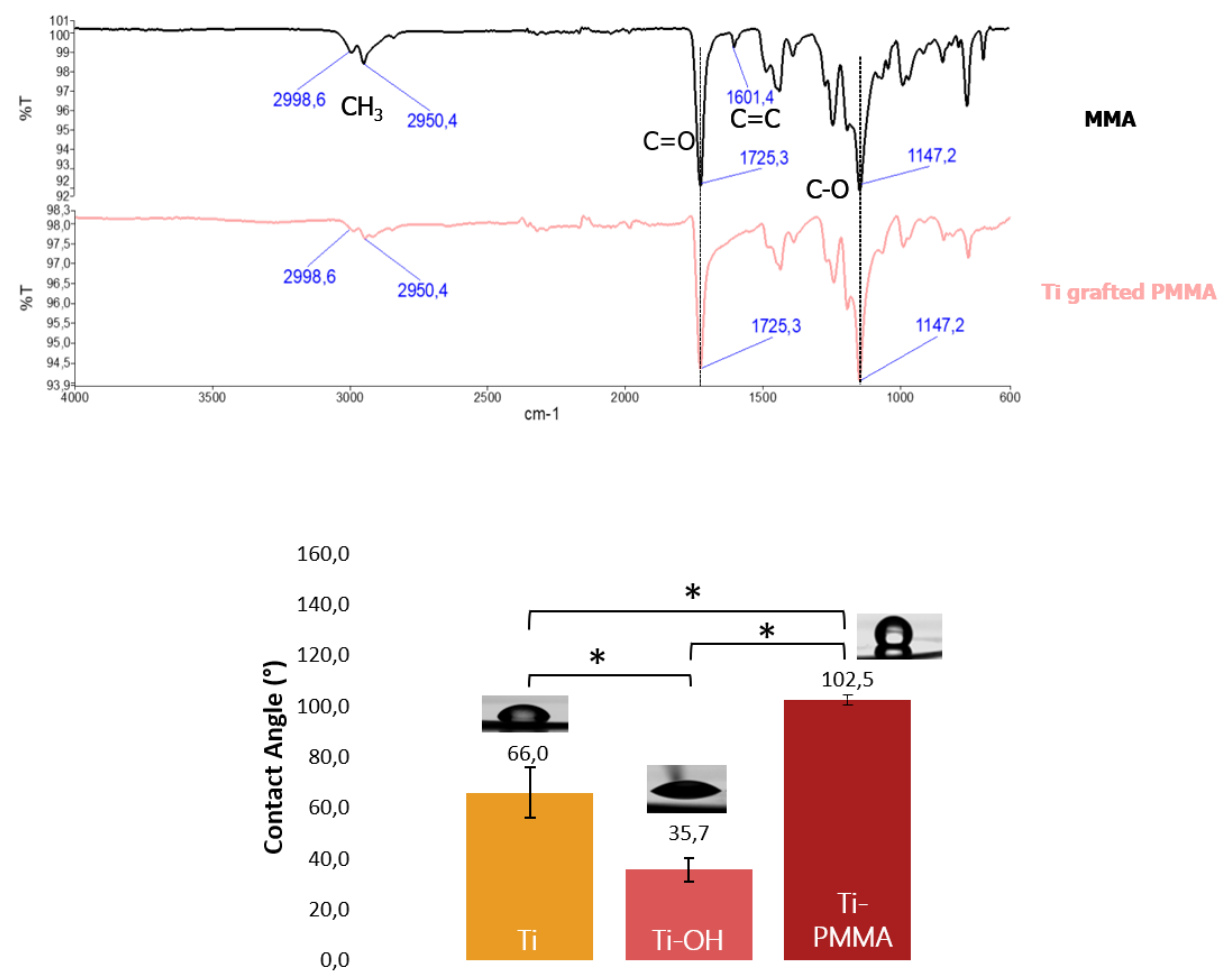

Figure 3: FTIR spectrum and WCA measurements result for the functionalized Ti with "grafting from" procedure.

\section{c. Double-face functionalization}

To confer bioactive properties to Ti surfaces, it has been decided to develop a method capable of grafting PMMA and PNaSS onto Ti. In this context, UV irradiation has been used, which produces a concentrated UV beam, to graft the Ti surfaces selectively. For this purpose, the Ti surfaces, suspended with Ti wires, were placed directly in contact with the UV beam (Figure 4). Thus, depending on the protocol used, the surface was able to graft the chosen polymer.

The double-face functionalization process was characterized by combining TB colorimetric assay, WCA measurements, FTIR and EDS.

The WCA measurement results (Figure 4) have attested to the presence of PMMA on the surface exposed to UV irradiation with PMMA grafting protocol ("grafting from" protocol), with the obtention of a contact angle of $102.0^{\circ} \pm 1.8$. On the order hand, the surface exposed to UV with PNaSS grafting protocol showed a contact angle of $25.0^{\circ} \pm 1.2$. PNaSS being an anionic and hydrophilic polymer, once grafted with PNaSS, the Ti surface should result in a low contact angle measurement. Thus, these results have demonstrated the presence of PMMA on one side of the Ti surface and PNaSS on the other side of the grafted Ti surfaces.

The TB results for the distinctive grafted surfaces were predictable with the contact angle results. Expecting 1 mol of TB complexes with $1 \mathrm{~mol}$ of sulfonate groups, TB provides data regarding the dispersion of the grafted PNaSS on Ti surfaces. As shown in Figure 4, the amount of PNaSS grafted $\left(0.7 \mathrm{M} 1 \mathrm{~h}\right.$ at the UV power $\left.160 \mathrm{~mW}^{-2} \mathrm{~cm}^{-2}\right)$ is $2.07 \pm 0.07 \mu \mathrm{g} . \mathrm{cm}^{-2}$ (Figure 4). The surface grafted with PMMA has shown no presence of PNaSS as the grafting degree of PNaSS onto this surface is equal to $0.05 \pm 0.02 \mu \mathrm{g} . \mathrm{cm}^{-2}$. Visually, the results of TB colorimetric assay are eloquent when comparing the surface grafted with PMMA and the surface grafted with PNaSS. The images (Figure 4) clearly show that the Ti-PNaSS surface gives a darker blue image due to the high concentration of 
sulfonate groups on the selectively grafted surface. Concerning the grafting degree of PNaSS, similar results have been obtained as Chouirfa et al. in the same condition with a power lamp at $160 \mathrm{~mW} . \mathrm{cm}^{-2}$, with $0.7 \mathrm{M}$ of monomer concentration and a UV exposure of 1h [27].

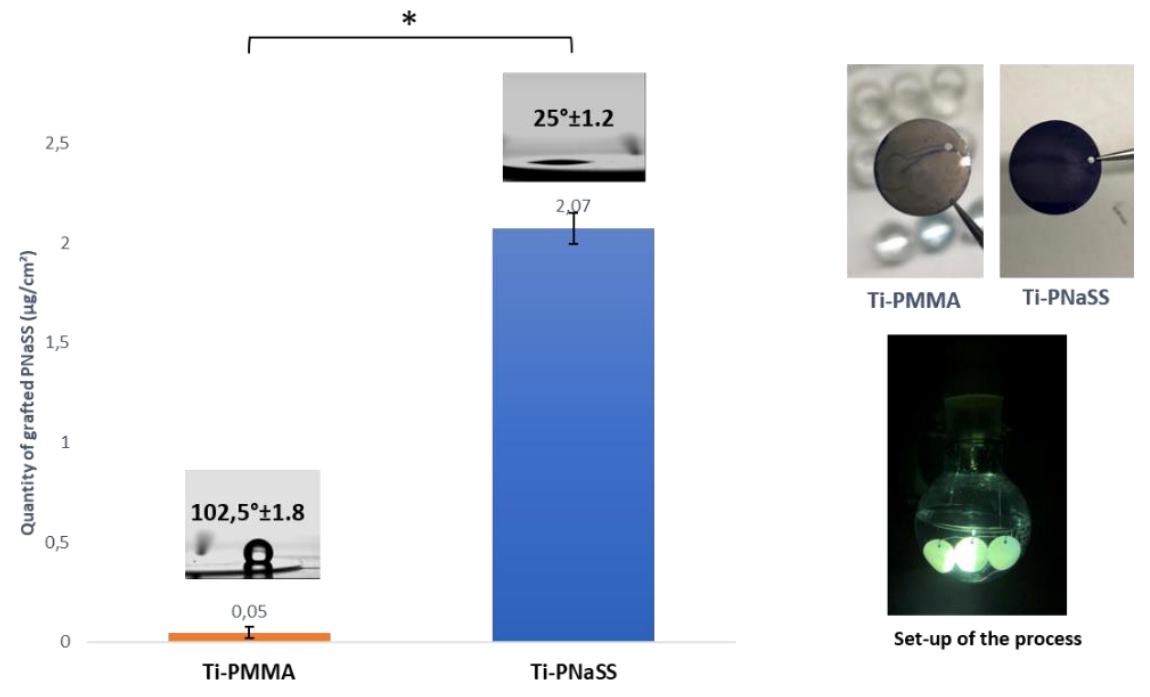

Figure 4: TB colorimetric assay, TB images results, WCA measurements, and set-up image of the "double-face functionalization" procedure.

Moreover, FTIR spectra of both sides of the grafted surface were done. The spectra (Figure 5) were assessed between 600 and $4000 \mathrm{~cm}^{-1}$. Ti-PMMA FTIR spectrum showed the presence of all the characteristics band of the PMMA. In addition, the Ti-PNaSS spectrum also showed the presence of specific peaks of the PNaSS at the surface of the Ti disk (Figure 5).

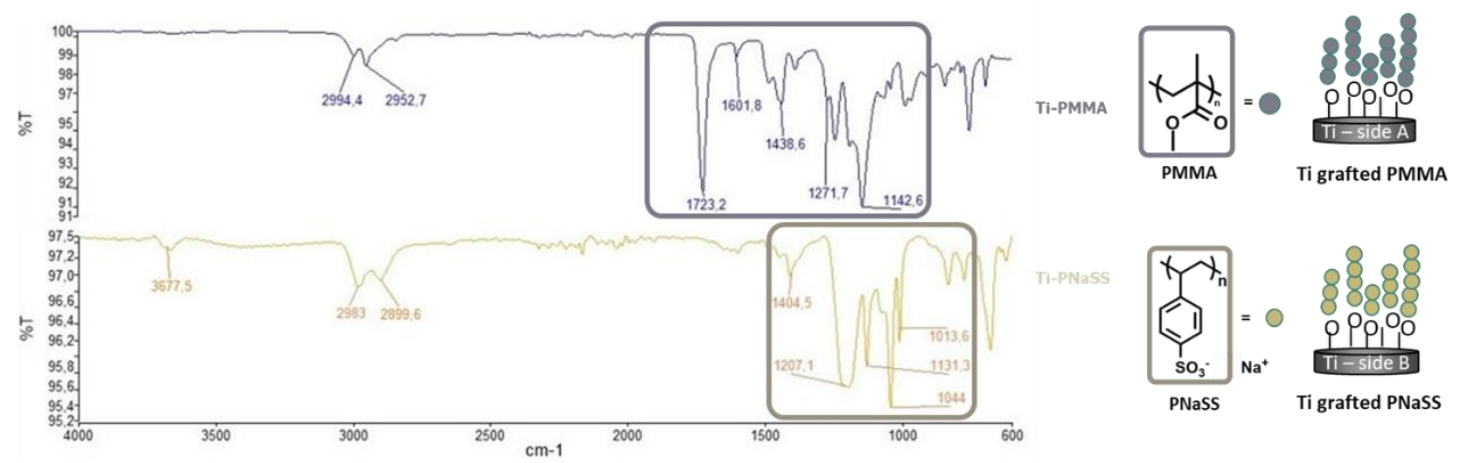

Figure 5: FTIR results of the surface selectively exposed to UV irradiation for the "double-face functionalization" procedure.

For instance, the FTIR spectrum of Ti-PNaSS shows the aromatic ring, and the symmetric vibrations of the $\mathrm{SO}_{3}{ }^{-}$groups generated a NaSS doublet $(\mathrm{O}=\mathrm{S}=\mathrm{O})$ located at $1013 \mathrm{~cm}^{-1}$ and $1044 \mathrm{~cm}^{-1}$. However, compared to the FTIR characterization work done for PNaSS [27], these two peaks are slightly shifted.

On the EDS analysis, the percentage of oxygen is more considerable after oxidation due to the oxide layer formation. The EDS element chemical analysis also showed $\mathrm{Na}$ and $\mathrm{S}$ atoms' presence, essential compounds of the PNaSS (Table 1) on the Ti-PMMA-Ti surface. In addition, a higher carbon percentage is observed; this result also confirms the grafting of the PNaSS. The FTIR results combined with EDS results demonstrate the selectivity of this double functionalization. 
Table 1: Analysis of atomic (\%) of elements at the Ti surface

\begin{tabular}{|c|c|c|c|c|c|}
\hline Samples & $\mathbf{C}$ & $\mathbf{O}$ & Na & S & Ti \\
\hline Ungrafted Ti & $5.1 \pm 0.5$ & $8.5 \pm 0.7$ & - & - & $86.4 \pm 0.6$ \\
\hline Activated Ti $(\mathbf{N a O H})$ & $9.1 \pm 0.4$ & $24.6 \pm 0.2$ & $0.4 \pm 0.1$ & - & $65.9 \pm 0.7$ \\
\hline UV PNaSS grafted Ti & $20.7 \pm 1.3$ & $19.8 \pm 1.5$ & $0.9 \pm 0.2$ & $1.0 \pm 0.4$ & $57.6 \pm 2.2$ \\
\hline UV PMMA grafted Ti & $40.9 \pm 1.2$ & $37.3 \pm 1.0$ & - & - & $21.8 \pm 1.7$ \\
\hline
\end{tabular}

\section{Conclusion and perspectives}

Thanks to the study carried out and reported in this article, the two grafting methods, "grafting to" and "grafting from" previously developed for the NaSS monomer, have been successfully transposed to another monomer such as MMA. This polymer is particularly interesting since it aims at improving the mechanical properties of the targeted Ti / PMMA / Ti sandwich structure.

The originality of our study is based on the development of a double functionalization of Ti surfaces. It has been shown by different characterizations (TB colorimetric method, WCA, FTIR, EDS) that it is possible to selectively graft a polymer to the surface of Ti using UV irradiation.

The protocol developed will allow us to functionalize the external surface of our sandwich structure. In addition, the osseointegration properties of the structure will be assessed using biological tests on osteoblast cells (MTT, morphology, alkaline phosphatase, and calcium assay). Besides improving the grafting time and being easily industrialized, the UV irradiation technique opens the door to numerous studies.

\section{Acknowledgments}

This research was supported by the French Ministry of National Education, Higher Education, and Research. The materials used in this study were financed by the ANR-DFG project (ANR-18-CE92-0056-01). We especially thank the ANR DFG for their financial support.

\section{Conflict of interest}

The authors declare that they have no conflict of interest.

\section{References}

[1] T.C. Origitano, R. Izquierdo and L.B. Scannicchio, Skull Base 5, 109 (1995).

[2] Y. Ducic, Journal of Oral and Maxillofacial Surgery 60, 272 (2002).

[3] T.P. Queiroz, R.S. de Molon, F.Á. Souza, R. Margonar, A.H.A. Thomazini, A.C. Guastaldi and E. HochuliVieira, Clin. Oral Invest. 21, 685 (2017).

[4] C. Debry, N.E. Vrana and A. Dupret-Bories, N. Engl. J. Med. 376, 97 (2017).

[5] A. Carradò, F. Perrin-Schmitt, Q.V. Le, M. Giraudel, C. Fischer, G. Koenig, L. Jacomine, L. Behr, A. Chalom, L. Fiette, A. Morlet and G. Pourroy, Dent. Mater. 33, 321 (2017).

[6] M. Szindler and T.G. Gaweł, Porous selective laser melted Ti and Ti6Al4V materials for medical applications. Powder metallurgy-fundamentals and case studies. (InTech.March 29th, 2017).

[7] S. Mueller, B. Hohlweg-Majert, R. Buergers, T. Steiner, T.E. Reichert, K.D. Wolff and K. Wolff, Clin Oral Invest. 19, 413 (2015). 
[8] A.L. Jardini, M.A. Larosa, R. Filho, C.A. Zavaglia, L.F. Bernardes, C. Lambert, D. Calderoni and P. Kharmandayan, J. Craniomaxillofac. Surg. 42,1877 (2014).

[9] H. Rotaru, R. Schumacher, S.G. Kim and C. Dinu, Maxillofac. Plast. Reconstr. Surg. 37,12 (2015).

[10] G.J. Huang, S. Zhong, S.M. Susarla, E.W. Swanson, J. Huang andC.R. Gordon, J. Craniofac. Surg. 26, 64 (2015)

[11] A. Ridwan-Pramana, P. Marcian, L. Borak, N. Narra, T. Forouzanfar andJ. Wolff, J. Craniomaxillofac. Surg. 44, 34 (2016)

[12] A. Sanan andS.J. Haines, Neurosurg. 40, 588 (1997).

[13] M. Ridzwan, S. Shuib, A. Hassan, A. Shokri and M.M. Ibrahim, J. Med. Sci. 7,460 (2007).

[14] M. Esposito, J. M. Hirsch, U. Lekholm, and P. Thomsen, Eur. J. Oral Sci. 106, 527 (1998).

[15] A. M. Roos-Jansaker, S. Renvert, and J. Egelberg, J. Clin. Periodontol. 30, 467 (2003).

[16] B. Harris, Mater. Des. 12, 259 (1991).

[17] R.F. Landel and L.E. Nielsen, Mechanical properties of polymers and composites. (CRC Press; 1993).

[18] E. L. Kostoryz, P. Y. Tong, C. C. Chappelow, J. D. Eick, A. G. Glaros and D. M. Yourtee. Dent Mater. 15, 363 (1999).

[19] M. Reggente, M. Harhash, S. Kriegel, W. He, P. Masson, J. Faerber, G. Pourroy, H. Palkowski and A. Carradò, Compos. Struct. 218, 107 (2019).

[20] J. E. Raynor, J. R. Capadona, D. M. Collard, T. A. Petrie and A. J. García. Biointerphases 4, FA3 (2009).

[21] A. Michiardi, G. Hélary, P. C. Nguyen, L. J. Gamble, F. Anagnostou, D. G. Castner and V. Migonney. Acta Biomater. 6, 667 (2010).

[22] F. El Khadali, G. Hélary, G. Pavon-Djavid, and V. Migonney, Biomacromolecules 3, 51 (2002).

[23] F. Anagnostou, F. Debet, G. Pavon-Djavid, Z. Goudaby, G. Hélary, and V. Migonney, Biomaterials 27, 3912 (2006)

[24] H. Felgueiras, M. Evans, and V. Migonney, Acta Biomater. 28, 225 (2015).

[25] H. Felgueiras and V. Migonney, IRBM 37, 165 (2016).

[26] C. Falentin-Daudré, V. Migonney, H. Chouirfa, and J. S. Baumann, WO patent PCT/EP2016/068909 (August 7th, 2015)

[27] H. Chouirfa, V. Migonney, and C. Falentin-Daudré, RSC Adv. 6, 13766 (2016).

[28] S. Minko, Polymer Surfaces and Interfaces, edited by M. Stamm (Springer, Berlin, 2008), pp. $215-234$.

[29] M. Reggente, P. Masson, C. Dollinger, H. Palkowski, S. Zafeiratos, L. Jacomine, D. Passeri, M. Rossi, N. E. Vrana, G. Pourroy and A. Carradò. ACS Appl. Mater. Interfaces 10, 5967 (2018).

[30] M. Kim, S. Schmitt, J. Choi, J. Krutty and P. Gopalan. Polymers 7, 1346 (2015).

[31] R. N. Foster, E. T. Harrison, and D. G. Castner, Langmuir 32, 3207 (2016).

[32] R. N. Foster, P. K. Johansson, N. Tom, P. Koelsh, and D. G. Castner, J. Vac. Sci. Technol. A 33, 05E131 (2015).

[33] R. N. Foster, A. J. Keefe, S. Jiang, and D. G. Castner, J. Vac. Sci. Technol. A 31, 06 F103 (2013).

[34] H. Chouirfa, M. Evans, D. Castner, P. Bean, D. Mercier, A. Galtayries, C. Falentin-Daudré and V. Migonney, Biointerphases 12, 02C418 (2017).

[35] H. Chouirfa, D. M. Evans, P. Bean, A. Saleh-Mghir, A.-C. Crémieux, D. G. C. Castner, C. Falentin-Daudré and V. Migonney, ACS Appl. Mat.Interfaces 10, 1480 (2018). 
[36] K. Zhang, J.A. Li, K. Deng, T. Liu, J.Y. Chen andN. Huang, Biointerfaces 108, 295 (2013).

[37] G. Helary, F. Noirclere, J. Mayingi and V. Migonney, Acta Biomater. 5, 124 (2009).

[38] N.P. Peksheva and V.M. Strukov, Russ. Chem. Rev. 48, 1092 (1979). 